\title{
State-of-the art review: Noncompaction cardiomyopathy in pediatric patients
}

\author{
Sofie Rohde ${ }^{1} \cdot$ Rahatullah Muslem $^{1} \cdot$ Emrah Kaya $^{1} \cdot$ Michel Dalinghaus $^{2} \cdot$ Jaap I. van Waning ${ }^{3}$. \\ Danielle Majoor-Krakauer ${ }^{3} \cdot$ Jeffery Towbin $^{4} \cdot$ Kadir Caliskan $^{1}{ }^{10}$
}

Accepted: 15 February 2021 / Published online: 14 March 2021

(c) The Author(s) 2021

\begin{abstract}
Noncompaction cardiomyopathy (NCCM) is a disease characterized by hypertrabeculation, commonly hypothesized due to an arrest in compaction during fetal development. In 2006, NCCM was classified as a distinct form of cardiomyopathy (CMP) by the American Heart Association. NCCM in childhood is more frequently familial than when diagnosed in adulthood and is associated with other congenital heart diseases (CHDs), other genetic CMPs, and neuromuscular diseases (NMDs). It is yet a rare cardiac diseased with an estimated incidence of 0.12 per 100.000 in children up to 10 years of age. Diagnosing NCCM can be challenging due to non-uniform diagnostic criteria, unawareness, presumed other CMPs, and presence of CHD. Therefore, the incidence of NCCM in children might be an underestimation. Nonetheless, NCCM is the third most common cardiomyopathy in childhood and is associated with heart failure, arrhythmias, and/or thromboembolic events. This state-of-the-art review provides an overview on pediatric NCCM. In addition, we discuss the natural history, epidemiology, genetics, clinical presentation, outcome, and therapeutic options of NCCM in pediatric patients, including fetuses, neonates, infants, and children. Furthermore, we provide a simple classification of different forms of the disease. Finally, the differences between the pediatric population and the adult population are described.
\end{abstract}

Keywords Noncompaction cardiomyopathy $\cdot$ Genetics $\cdot$ Heart failure $\cdot$ Pediatric $\cdot$ Children $\cdot$ Review

$\begin{array}{ll}\text { Abbreviations } \\ \text { CMR } & \text { Cardiac magnetic resonance imaging } \\ \text { Htx } & \text { Heart transplantation } \\ \text { IQR } & \text { Interquartile range } \\ \text { LV } & \text { Left ventricle } \\ \text { Med } & \text { Median }\end{array}$

Kadir Caliskan

dr.kcaliskan@hotmail.com

1 Thoraxcenter, Department of Cardiology, Erasmus University Medical Center, Room RG 431, 3015 GD Rotterdam, The Netherlands

2 Division of Pediatric Cardiology, Sophia Children's Hospital, Erasmus University Medical Center Rotterdam, Rotterdam, The Netherlands

3 Department of Clinical Genetics, Erasmus University Medical Center, Rotterdam, The Netherlands

4 The Heart Institute, Le Bonheur Children's Hospital, Memphis, TN, USA

\section{Introduction}

Noncompaction cardiomyopathy (NCCM) is heterogenous cardiomyopathy characterized by multiple prominent trabeculations and deep intertrabecular recesses. It is a relatively new, rare disease entity that has only been recognized as a distinct cardiomyopathy since 2006 [1].

Since its first description in 1984 by Engberding et al. [2], NCCM has been labeled with several names over the last 35 years including spongy myocardium, left ventricular noncompaction cardiomyopathy (LVNC), and left ventricular hypertrabeculation (LVHT) [3, 4]. In this paper, we will use NCCM as the main term to address this disease, in analogy to the terminology of dilated cardiomyopathy (DCM), hypertrophic cardiomyopathy (HCM), and restrictive cardiomyopathies (RCM) and given the involvement of right ventricular involvement in many patients $[5,6]$.

Although NCCM is a rare cardiac disease, it is the third most common cardiomyopathy (CMP) in the pediatrics following DCM and HCM [7]. NCCM can cause heart failure and is associated with thromboembolic events and (fatal) arrhythmias in adults [8]. In addition, NCCM can occur as 
an isolated or non-isolated phenotype. Non-isolated NCCM may be accompanied by congenital heart diseases (CHDs), features of other CMPs, and/or neuromuscular diseases (NMDs) [9, 10].

The pathophysiology of NCCM is not completely understood and there are different theories of how the extensive trabeculations are formed. One of those is that NCCM is caused by abnormal embryological compaction of the myocardium, leading to a hypertrabeculated honeycomb-like myocardium $[11,12]$. However, this does not explain NCCM diagnosed in adulthood. Many genes have been reported to be associated with NCCM, but none of the proposed pathogenic gene variants or chromosomal defects can directly be linked to a disrupted compaction process in the fetus. Furthermore, most of the (likely) pathogenic gene variants can lead to different phenotypes [13].

Due to its rarity, the lack of universally accepted diagnostic criteria, and the lack of awareness among the clinicians, little is known about NCCM in children. In particular, very few cases of fetal NCCM diagnosis have been reported [14, 15]. Among those are cases caused by pathogenic MYH7 gene variant. These observations do not support or explain abnormal myocardial maturation during gestation. Genetic counseling is needed to provide risk estimates and inform patients and relatives. In case of an increased risk in a pregnancy prenatal echocardiography can be offered. However intra-familial phenotypic variability hampers prediction of age at onset and expected severity of feature [14]. In families where the genetic cause for NCCM has been identified, DNA testing of relatives and also prenatal DNA diagnostics can be performed [13].

The purpose of this paper is to discuss the clinical presentation, outcome, therapeutic options, natural history, and epidemiology of NCCM in pediatrics, including fetuses, neonates, infants, and children. Furthermore, we provide a simple classification of different forms of the disease. Finally, the differences between the pediatric population and the adult population are described.

\section{Historical perspective}

The first case of NCCM was probably described by Bellet and Gouley in 1932 as a rare complex congenital myocardial anomaly [16]. They performed an autopsy on a newborn infant and found remains of the sinusoids of the embryonic heart and deep invaginations of the endocardium. However, in 1984, echocardiography allowed for the first diagnosis of an isolated NCCM, without concomitant structural CHD, in a living patient [2]. In 2006, an expert panel of the American Heart Association introduced NCCM as a distinct form of cardiomyopathy defined as a primary genetic heart disease characterized by a spongy myocardial appearance, predominantly involving the apex of the left ventricle, caused by an arrest in normal embryogenesis [1]. In contrast, the European Society of Cardiology (ESC) does not classify NCCM as a distinct cardiomyopathy [17]. Technological advancements in cardiac imaging in the last decades and increasing clinical awareness have allowed for more frequent recognition of NCCM.

\section{Epidemiology}

The exact incidence of NCCM in children has not been established yet, due to the relatively recent classification as a distinct form of cardiomyopathy. Furthermore, consensus about diagnostic criteria has not yet been reached, leading to a delay in the diagnosis of NCCM or NCCM to be misdiagnosed as another form of CMP, such as DCM [18]. Differentiation of NCCM from DCM and NCCM with features of DCM could be important since treatment, prognosis, and rates of family occurrence may differ.

The estimated incidence of NCCM is 0.12 per 100.000 in children up to ten years of age and $\leq 0.81$ per 100.000 in children up to one year of age [6]. NCCM is therefore considered as the third most common form of cardiomyopathy in children [6]. In addition, several smaller cohort studies in pediatric patients reported similar incidence rates. An Australian study reported an incidence of NCCM in $9.2 \%$ of all children diagnosed with a primary CMP under the age of ten between 1987 and 1996 [7]. Furthermore, according to the Pediatric Cardiomyopathy Registry (PCMR), a large register including 98 centers from the USA and Canada, $4.8 \%$ of all children diagnosed with any form of CMP had an isolated NCCM, over a period of 18 years [19]. Nonetheless, uniform diagnostic criteria and international registries are still warranted to determine the exact incidence and prevalence of NCCM.

\section{Pathophysiology}

NCCM may involve abnormal myocardial embryogenesis. The heart forms as a simple tube with only two layers of cells, one epithelial and one endothelial, with a cardiac substance in between [20]. As the heart grows in mass, the cardiac substance is replaced by muscle tissue [20]. This newly formed muscle tissue is constructed in a sponge-like structure, enabling the cells to be oxygenated and receive nutrients through the blood flow in the endothelial outlined spaces, because of the absence of the coronary and sinusoidal circulation $[11,12,21]$. Normally, compaction of the myocardium takes place in weeks 5-8 of the fetal life, from basal to apical segments and from septal to lateral walls. In congenital NCCM, it is believed that genetic defects or 
epigenetic regulation of specific cardiac pathways cause an arrest in the normal process of myocardial compaction resulting in a myocardium consisting of two layers: one compact layer (epicardium) and one honeycomb-like structure with extensive ventricular trabeculation and deep intertrabecular recesses (endocardium) [11, 12, 20, 21].

Autopsy of a patient with isolated persisting myocardial sinusoids of both ventricles, an earlier terminology to define NCCM, shows the following features: hyperplastic trabeculae separated by labyrinthic spaces communicating with the ventricular cavity, an extended pericardial sac and thickening of the heart, mostly pronounced in the apical region [12]. Nonetheless, this bilayer structure of NCCM should be differentiated from trabeculae in the apex of the heart, which can be seen in healthy individuals. In the latter, the thickness of the trabecular layer does not usually exceed the compact layer in size, as in the case in NCCM [11, 12, 21].

NCCM predominantly affects the left ventricle, both in children and adults. To date, few cases of biventricular noncompaction in children are reported [22-27]. Furthermore, in the left ventricle, NCCM predominantly affects the apex. This can be explained by the fact that compaction of the heart proceeds from base to apex and form septal to lateral. However, the LV posterior wall may have hypertrabeculation as well.

\section{Pediatric NCCM phenotypes}

Pediatric NCCM is typically a non-isolated phenotype that is often associated with concomitant features of other CMPs (mixed phenotype) or in the coexistence of one or more structural CHD(s), malformation syndrome, metabolic disorders, or NMD [13]. In contrast, the isolated form of NCCM is the most predominant phenotype in adult patients.

\section{NCCM with a mixed phenotype}

NCCM patients could present with features of another CMPs. Of the pediatric patients, $30.4 \%$ also present with DCM characteristics, $18.7 \%$ with HCM characteristics, and $17.9 \%$ with both DCM and HCM characteristics. Only $32.2 \%$ of the pediatric NCCM cases are without any features of another CMP (Fig. 1) [7, 28-33].

\section{NCCM with concomitant CHD}

Pediatric NCCM has been reported with structural CHD [30-32, 34-39]. Initially, it was thought that NCCM only exists in the presence of CHD. The exact incidence of CHD in the NCCM population is unknown with incidence rates reported varying from 13 to $78 \%$ (Table 1). Ventricular septal defect (VSD; 18.7\%), atrium septum defect (ASD;

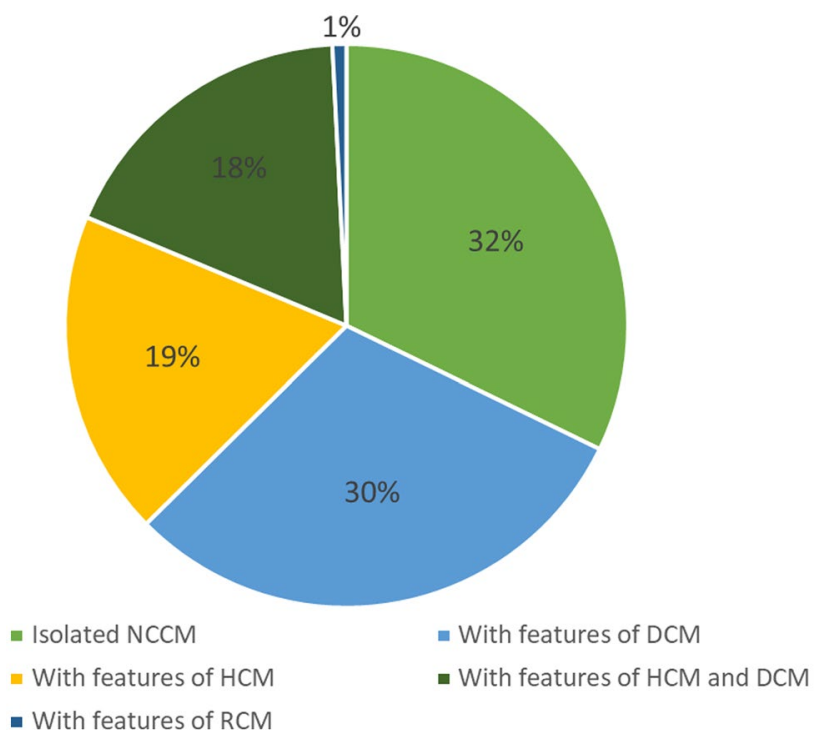

Fig. 1 Concomitant features of other cardiomyopathies. Summarized data of the included cohort studies [7, 28-33]. DCM dilated cardiomyopathy, HCM hypertrophic cardiomyopathy, NCCM noncompaction cardiomyopathy, RCM restrictive cardiomyopathy

$10.8 \%$ ), persistent ductus arteriosus (PDA; 6.3\%), and Morbus Ebstein $(4.1 \%)$ are the most reported forms of CHD in association with NCCM in the pediatric populations (Fig. 2a) [30-32, 34-39]. Figure $2 b$ depicts the concomitant appearance of the three most common CHDs in the pediatric NCCM population.

\section{NCCM with concomitant NMD}

Many NMDs eventually affect the cardiac muscle [40]. Consequently, NMDs are more frequently seen in cardiomyopathy populations, which also apply to the NCCM population [41]. The first described NMD patient with NCCM was an adult patient with Duchenne muscular dystrophy (DMD) [42]. The incidence of DMD in the pediatric NCCM population is unknown. However, the incidence of NCCM in the DMD population is reported near 20-25\% [43, 44]. Little is known about the incidence of other neuromuscular disorders, like metabolic myopathy, Becker and Limb-Girdle syndrome [40], in the pediatric NCCM population and more research is warranted.

Another NMD associated with NCCM is Barth syndrome. This is syndrome will be discussed later.

\section{Fetal NCCM}

If NCCM was an arrest in embryonic trabeculation, it should, in theory, be detectable at prenatal echocardiography. However, only a few cases of fetal NCCM diagnosis have been reported in the literature [14, 45-48]. Fetal 


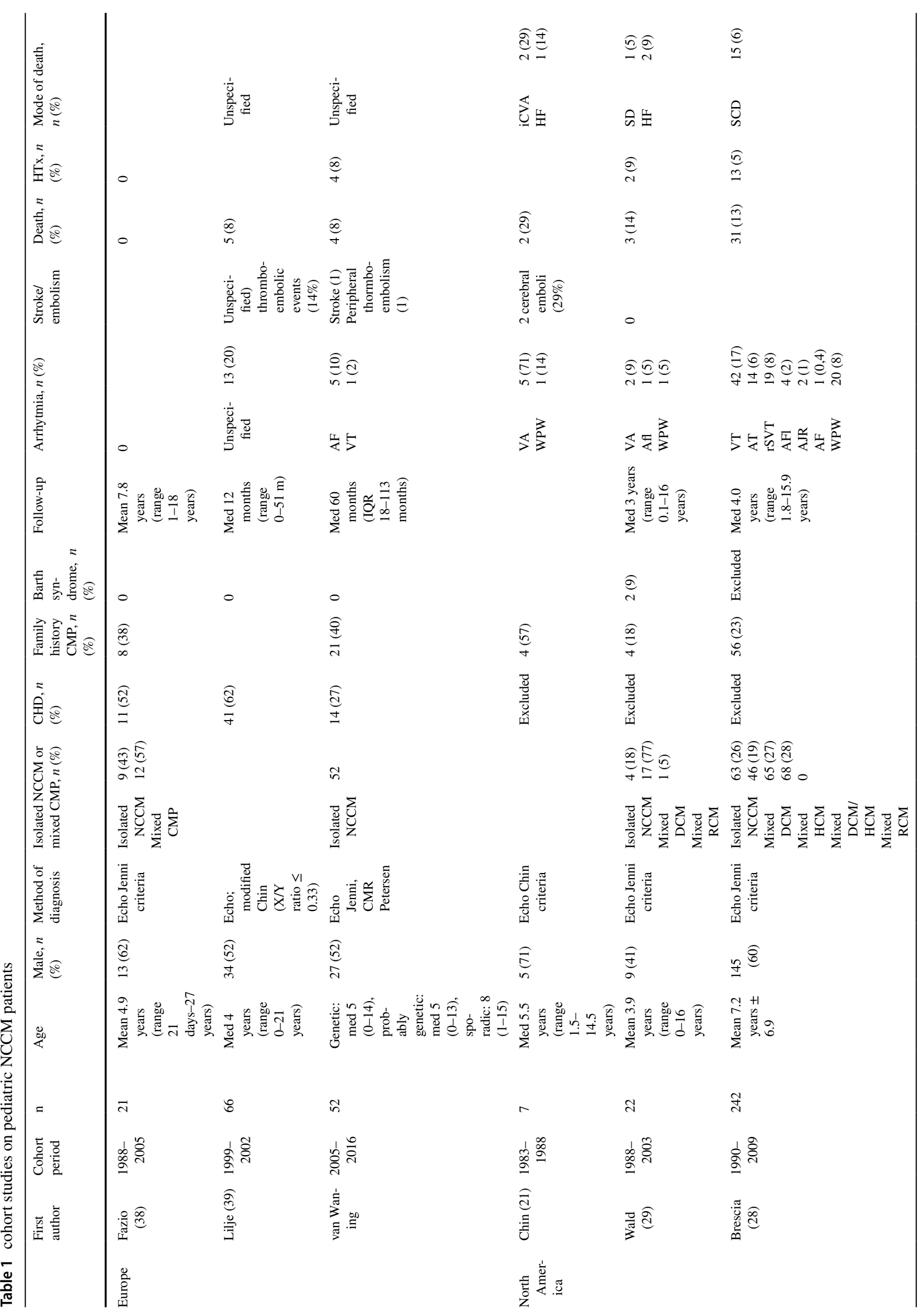




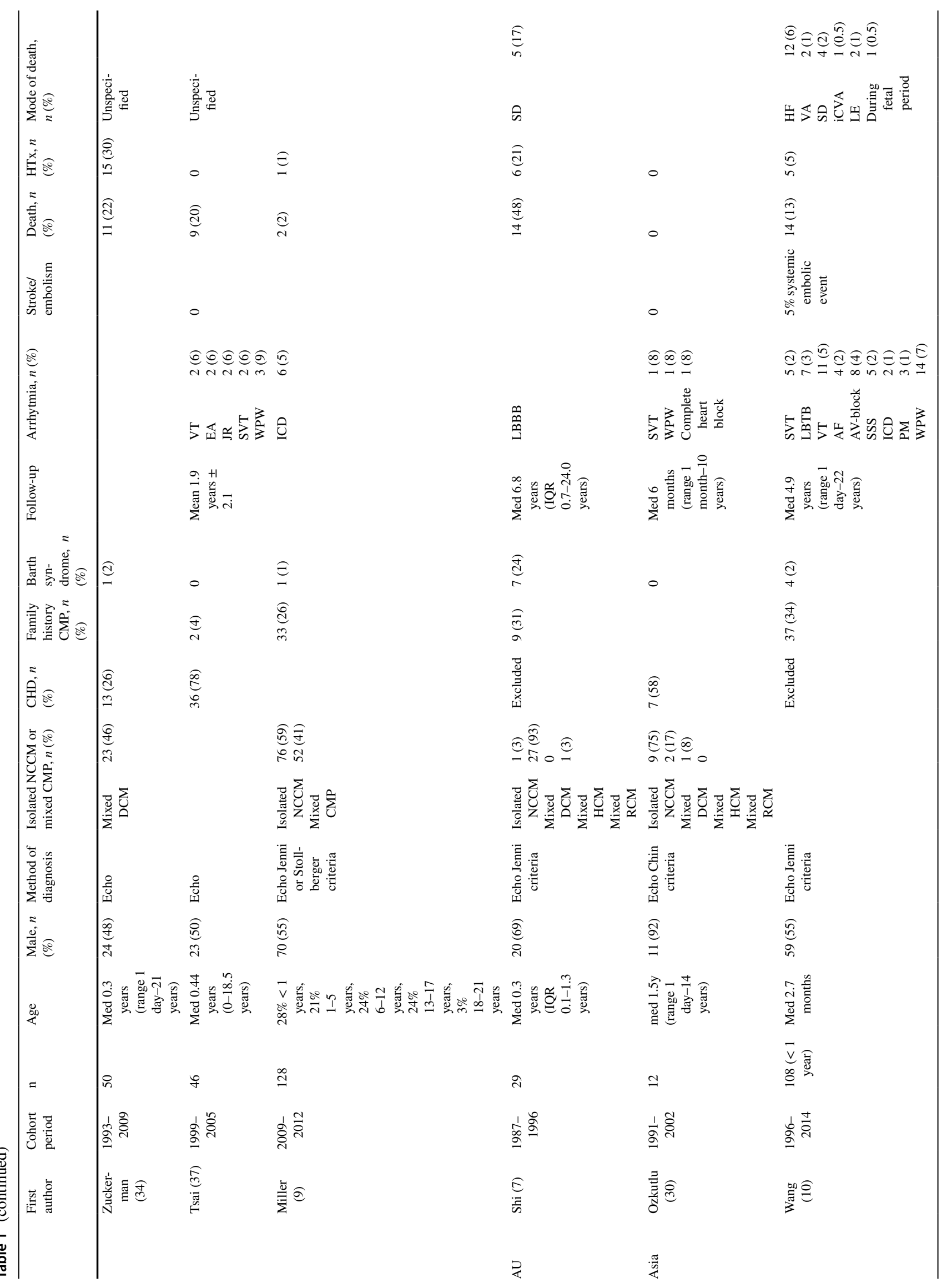




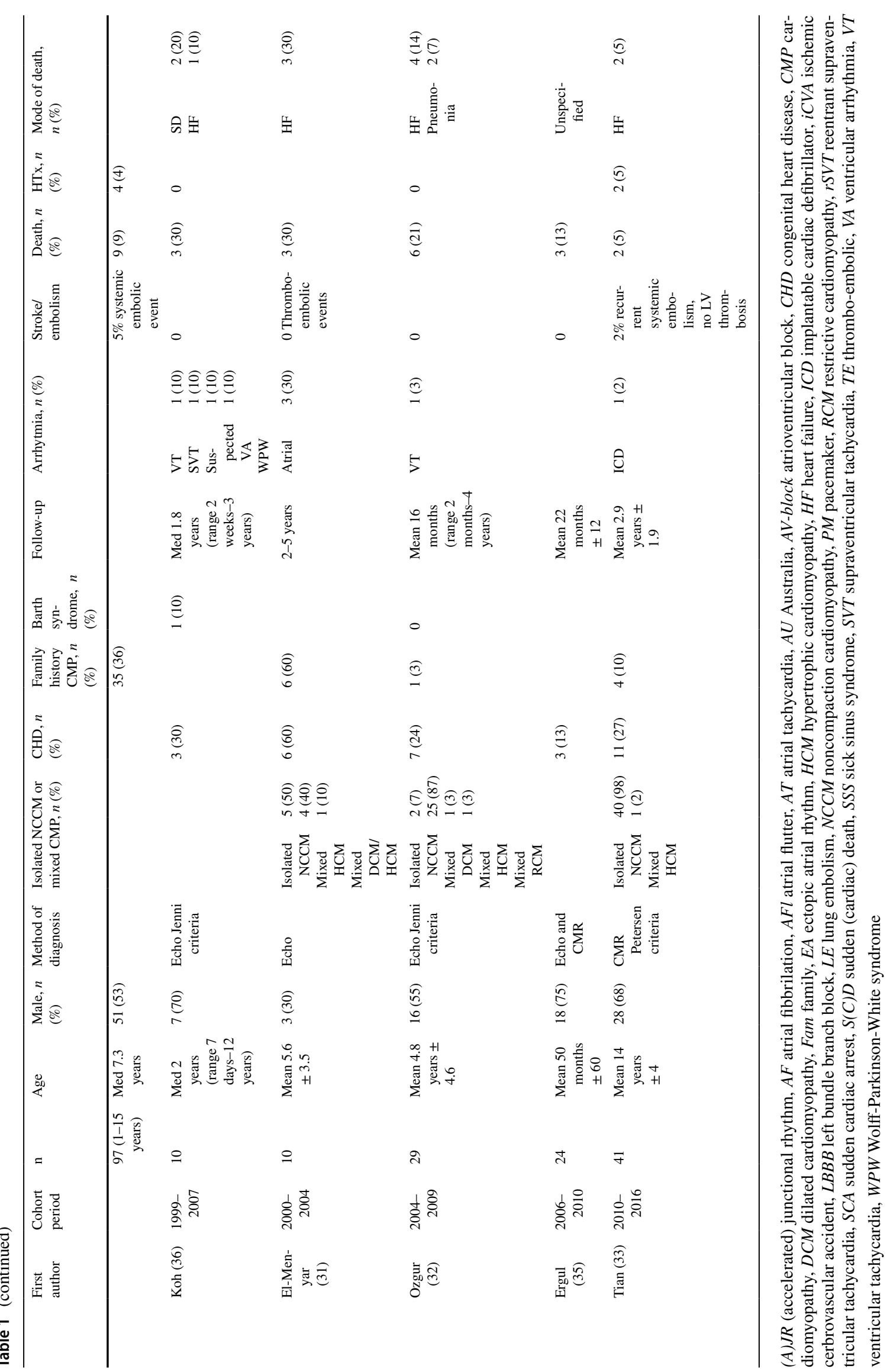


Fig. 2 Combined percentages of concomitant congenital heart diseases reported in the included NCCM cohort studies [30-34, 36-39]. b Concomitant appearance of the three congenital heart defects mostly associated with noncompaction cardiomyopathy in children [30-34, 36-39]. ASD atrium septum defect, CHD congenital heart disease, PDA persistent ductus arteriosus, VSD ventricle septum defect

\begin{tabular}{|l|l|}
\hline Concomitant CHD & $\%$ \\
\hline VSD & $18.7 \%$ \\
\hline ASD & $10.8 \%$ \\
\hline PDA & $6.3 \%$ \\
\hline Morbus Ebstein & $4.1 \%$ \\
\hline Aortic valve stenosis & $3,7 \%$ \\
\hline Aortic coarctation & $3.4 \%$ \\
\hline Pulmonary valve stenosis & $2.6 \%$ \\
\hline Tetralogy of Fallot & $1.9 \%$ \\
\hline
\end{tabular}

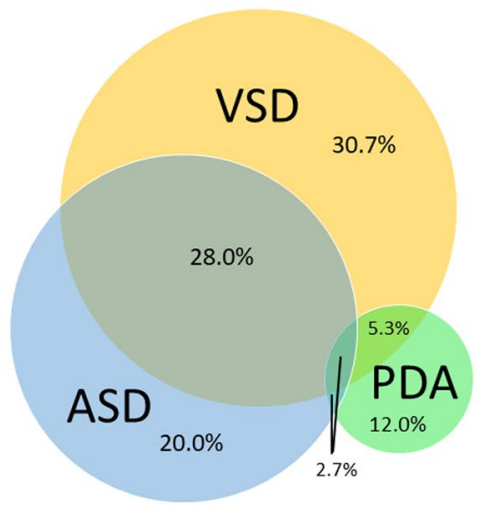

hydrops was present in $33 \%$ of these cases and other structural cardiac abnormalities in $60 \%$ of patients [49]. The concomitant structural cardiac abnormalities most frequently reported in the fetal NCCM population were atrioventricular septal defect (33\%), double-outlet right ventricle (26\%), and left atrial isomerism (24\%). The presence of Ebstein's anomaly was not reported in this population [49].

The fetal NCCM population shows a trend towards a worse survival (37.5\%, mean age 26 months). In addition, 9.1\% died prenatally, $27.3 \%$ died after birth, and in $19.3 \%$ the parents decided to terminate the pregnancy. Also, $6.8 \%$ was lost to follow-up [49]. The seemingly worse survival in prenatal diagnosed NCCM patients could be due to the rareness of this new disease entity with publication bias, because prenatal echocardiography may only recognize the most severe cases [50].

\section{Genetics}

NCCM, like most familial CMPs, is a genetic heterogeneous disease. Although this is a relatively young field of expertise, over 40 monogenetic and chromosomal defects are described in the overall NCCM population [51, 52]. Different inheritance patterns are described in NCCM [51-54] and the exact mechanism of how certain gene mutations can lead to NCCM is unknown. The same genetic defects are associated with different phenotypes, and the same genetic pathogenic variants can result in both overlapping and divergent cardiac manifestations, even within the same family. More importantly, a genotype-phenotype correlation has recently been established showing that specific genes may confer risk for overlapping cardiomyopathy phenotypes, like NCCM/DCM and NCCM/HCM within families [20, 52-55]. Furthermore, genetic defects are more often found in pediatric NCCM patients compared to the adult population [13]. However, since childhood NCCM is rare and routine genetic testing has not yet been widely applied, very limited data on the various (likely) pathogenic variants in pediatric NCCM exists. However, in our recent study we found a clear association with major adverse cardiac events and (probably) genetic NCCM, or familiar the genotypes, especially in children with multiple mutations in MYBPC3 $(p=0.006)$, along with presentation in neonates and very young children aged $<1$ (HR of $2.1, p=0.004$ ) [13]. Future studies with comprehensive genetic testing could learn us more about the pathophysiology of NCCM, the incidence and severity of arrhythmias, risk of sudden cardiac death (SCD), and development of heart failure.

\section{Autosomal inheritance}

In the overall NCCM population, various autosomal inherited genetic defects, mostly with dominant inheritance, were associated with NCCM, including pathogenic variants in sarcomere or cytoskeletal genes, and genes encoding ion channels. The sarcomere $M Y H 7$ and $M Y B P C 3$ genes are most frequently reported to cause NCCM (20-25\% and $10 \%$, respectively) [54]. Certain autosomal defects in other genes encoding proteins such as $\alpha$-dystrobrevin, $\alpha$-cardiac actin, and cardiac troponin $\mathrm{T}$ are also responsible for DCM and HCM. This implicates a possible similar molecular etiology to various cardiomyopathy phenotypes [8, 56-59]. Furthermore, DCM or HCM is often diagnosed in family members of NCCM patients. Interestingly, NCCM with features of DCM was associated with mutations in the tail of $M Y H 7$ ( $p$ $<0.001)$ and NCCM with features of HCM was associated with $M Y B P C 3(p<0.001)$ [55].

In NCCM pediatric patients had concomitant congenital heart disease, the existing literature in these is scarce, but in a systemic review, most frequent mutations were in $\mathrm{MYH} 7$, MIB2, MKX2, NOTC1, NSD1, PTPN2, and a whole range of chromosomal defects [60].

\section{X-linked}

The first pathogenic gene variant found to be responsible for NCCM was a genetic variant in the $T A Z$ gene, on locus 
Xq28, with X-linked recessive inheritance. $T A Z$ encodes for the protein tafazzin. Tafazzin is mostly expressed in cardiac and skeletal muscles and is involved in the metabolism of cardiolipin. Cardiolipin is important in maintaining the mitochondrial structure. Several other systemic myopathies, such as Barth syndrome, which is mostly accompanied by DCM, NCCM, or both, are also caused by a defect in this gene $[61,62]$.

Barth syndrome, or 3-methylglutaconic aciduria, is an $\mathrm{X}$-linked metabolic disorder characterized by skeletal and cardiac myopathy, growth delay, and neutropenia in males [63]. It was first described by Harry Neustein in 1979 [64] and by a Dutch doctor named Peter Barth in 1983 [65]. Ninety percent of the boys with this extremely rare disease develop a form of cardiomyopathy [66]. In addition, 70\% of these children were diagnosed with a CMP under 1 year of age, and all of them under the age of 5 [66]. In children with NCCM, the reported incidence rates of Barth syndrome range from 0 to $24 \%$, with most studies reporting an incidence of $0 \%$ (Table 1) [7, 9, 10, 29, 30, 32, 34, 36-39]. The study that reported an incidence of $24 \%$ was a small study that included only 29 patients. Nevertheless, the wide incidence rate demonstrates this distinct cause for NCCM is frequently reported, even though the prevalence of Barth syndrome is low.

DMD, the first NMD in which NCCM concomitance was described, also follows an X-linked inheritance.

Interestingly, there is a possible difference in genetic pathophysiology between adult and pediatric patients. For example, genetic analyses performed on 25 adult patients showed no mutations in the $T A Z$ gene. In addition, most of these adult patients presented with an autosomal dominant inheritance pattern, leading to the speculation that isolated NCCM in adults is mostly caused due to an autosomal dominant disorder, and therefore genetically distinct from pediatric X-linked causes [67].

\section{Mitochondrial}

Various mitochondrial DNA (mtDNA), as well as nuclear genes involved in the oxidative phosphorylation, are linked to NCCM [52, 59]. Since Mt DNA diagnostics are not performed routinely for NCCM, the contribution of mtDNA pathogenic variants in NCCM may be larger [68].

\section{Clinical presentation}

Children with non-isolated NCCM mostly present with the symptoms of their CHD [30].

The most common clinical presentation of isolated NCCM in children is congestive cardiac failure (Fig. 3) [7, 10, 21, 28, 29, 31-33, 35-38]. However, patients with

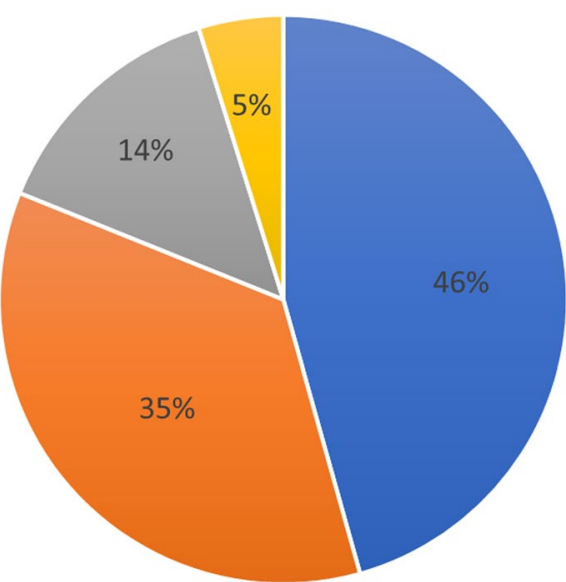

- Congestive cardiac failure - Arrhythmia/ syncope

- Asymptomatic/family screening w other

Fig. 3 Initial presentation of noncompaction cardiomyopathy in children. Summarized data of the included cohort studies [7, 10, 21, 28, 29, 31-33, 35-38]

isolated NCCM can also be asymptomatic and diagnosed after an abnormal ECG, echocardiogram, chest X-ray, or simply after an abnormal cardiac exam. In contrast to adults, arrhythmia, chest pain, syncope, and (aborted) SCD are less common presenting symptoms in pediatric NCCM patients (Table 1).

Although the median age at presentation ranges between 0.3 and 5 years [7, 21, 30, 34, 36, 37, 39], several studies reported that children with NCCM are mostly diagnosed under the age of 1 year [9, 10, 28, 30, 34, 69].

In addition, pediatric NCCM patients with an HCM or DCM phenotype are significantly younger than NCCM patients without any concomitant features $(9.3$ years versus 0.4-0.6 years, $p<0.001$ ) [19]. Furthermore, in comparison to pediatric patients with DCM, pediatric patients with NCCM listed for heart transplantation are significantly younger (3.1 \pm 4.3 years versus $6.9 \pm 6.3$ years, $p<0.0001)(70)$.

Interestingly, some pediatric patients show an improvement in their cardiac function after the initial diagnosis of NCCM. A brief period of myocardial recovery, prior to deterioration, proceeds. This so-called undulating phenotype may be an explanation for the presentation in adulthood [69]. For example, a national population-based study with a median follow-up of 24.7 years of all survivors found that normalization of left ventricular systolic function occurred in 8 of the 29 subjects (28\%). Two of them later died suddenly and four of them showed reduced cardiac function at later follow-up [7].

Additionally, familial screening in NCCM has proven to be of significant value, since we found a combined incidence of $25.4 \%$ of the children diagnosed with NCCM to have a 
positive family history of NCCM or another form of CMP (Table 1) [7, 9, 10, 21, 28, 29, 31-33, 37, 38]. Furthermore, the NCCM phenotype of a patient may help predict CMP phenotypes and outcomes in relatives [55].

\section{Diagnostic}

The diagnosis of NCCM is usually made through echocardiography or CMR according to the morphological criteria. Different echocardiographic criteria are proposed in the past 30 years to distinguish NCCM from physiological trabeculation and other forms of cardiomyopathy. The two most commonly used echocardiographic criteria are the Jenni criteria [4], the Chin criteria [21], and the Stöllberger criteria [71].

Most criteria, however, have poorly tested pathoanatomic correlation $[4,21,72]$, and it is important to note that almost a fourth of the heart failure population fulfil one or more of these echocardiographic criteria. This suggests that the current echocardiographic criteria's are not distinctive enough for NCCM.

Therefore, our group proposed the Rotterdam criteria, combining both conventional trabeculation criteria (i.e., the "Jenni criteria") and septal thickness (Fig. 4) [18]. These criteria differentiate between definite NCCM and a normal variant seen in athletes, African descendants, and long-standing hypertension [18]. Furthermore, differentiation between the fully asymptomatic patients with normal ECG, cardiac function, and genetics, i.e., not a disease in a narrow sense, is important because of the potential huge psychological, social, legal, and insurance consequences. Furthermore, eventual concomitant CHD or NMD should not be an exclusion criterion.

If uncertainty about the diagnosis of NCCM still exists, additional diagnostics, such as CMR, are warranted [73]. For CMR, the Petersen criteria are most frequently used in clinical practice [74]. NCCM can be distinguished from physiological trabeculation and other CMPs, such as HCM, through CMR, by a noncompacted layer to compact layer ratio of 2.3 (sensitivity of $86 \%$, specificity of $99 \%$ ) or a trabeculated LV mass ratio of $>20 \%$ (sensitivity and specificity of $94 \%)[74,75]$. These cohort studies were, however, rather small, and a larger, more recent study $(n=1480)$ showed that these features were present in $12.6 \%$ and $4.1 \%$ respectively of the healthy (adult) volunteers [76]. Interestingly, a recent study showed that meeting the Petersen criteria in $\geq 2$ out of

\section{Modified Rotterdam Criteria of NCCM}

Clinical evaluation, including ECG, echocardiography (/CMR), genetic testing

\begin{tabular}{|c|c|c|}
\hline \multicolumn{3}{|c|}{$\begin{array}{l}\text { Echocardiographical features of Noncompaction Cardiomyopathy } \\
\text { - Abnormal segmental myocardial thickening of LV or RV due to hypertrabeculation with two-layered } \\
\text { pattern } \\
\text { - Thickend noncompacted (N) endocardial layer with a compacted }(\mathrm{c}) \text { thin epicardial layer } \\
\text { - NC/C ratio }>2 \text { in PSLX end-systole } \\
\text { Segmental or global cardiac dysfunction } \\
\text { - No septal hypertrophy }(<12 \mathrm{~mm})\end{array}$} \\
\hline $\begin{array}{l}\text { - Cardiac symptoms } \\
\text { Family history of heart } \\
\text { failure, sudden cardiac } \\
\text { death and/or } \\
\text { neuromuscular diseases } \\
\text { - Abnormal ECG }\end{array}$ & $\begin{array}{l}\text { - Asymptomatic } \\
\text { - Negative family history and } \\
\text { - Nonetic testing } \\
\text { - Normal ECG } \\
\text { - Morphol cardiac function } \\
\text { - }\end{array}$ & $\begin{array}{c}\text { Not fulfilling morphological } \\
\text { NCCM criteria: } \\
\text { Left ventricular } \\
\text { hypertrabeculation (LVNC) } \\
\text { (e.g. chronic volume or pressure }\end{array}$ \\
\hline $\begin{array}{c}\text { Definitive } \\
\text { diagnosis of NCCM }\end{array}$ & NCCM "trait" & $\begin{array}{c}\text { hypertensive heart disease, } \\
\text { athletes' heart, } \\
\text { normal variant in African } \\
\text { descendants) }\end{array}$ \\
\hline
\end{tabular}

Fig. 4 Diagnosing NCCM according to the Rotterdam criteria [18]. LVNC left ventricular noncompaction, NCCM noncompaction cardiomyopathy, NMD neuromuscular disease, PSLX parasternal long axis view 
3 long-axis views was an independent predictor for having a likely pathogenetic variant in adult NCCM patients who fulfilled the echocardiographic Jenni criteria [77].

Although echocardiography and CMR are frequently used to diagnose NCCM, no genetic, histopathological, or imaging diagnostic tool has been developed yet which can distinguish NCCM patients from physiologic hypertrabiculation of the left ventricle. The use of echocardiography and CMR has resulted in an exponential growth in the recognition of NCCM over the past 10 years. In a large multicenter study in North America, including 98 centers, 217 patients were diagnosed with NCCM between 2000 and 2009, while between 1990 and 1999 , only 25 NCCM patients were identified [28]. This gain in "popularity" can be due to the raised awareness or the more flexible interpretation of the diagnostic criteria since various other disorders of the myocardium show high similarity [78].

Routine genetic testing is currently performed, albeit for now, there are no genes related specifically to NCCM and not to other cardiomyopathies [53, 54]. Furthermore, the same pathogenic gene variant can cause highly variable phenotypes [13]. However, if a family is known to be affected by a certain pathogenic gene variant, a molecular genetic analysis could be useful to identify other affected (asymptomatic) family members (cascade testing). Furthermore, genetic analyses should be considered, if the parents wish to have a child, to estimate the chance of re-occurrence. This is especially useful in case of (possible) childhood-onset NCCM, and in complex disorders presenting with NCCM, like in Barth syndrome. Genetic analysis yields the genetic cause in approximately $45 \%$ of childhood NCCM and may help determine the risk of recurrence and pathophysiology of NCCM [13].

\section{Natural history and prognosis}

Reported outcomes in pediatric NCCM patients differ widely. An Australian study found that in 10 years after the diagnosis of NCCM with a dilated phenotype, half of the pediatric patients died or underwent HTx and that only 20\% of the pediatric patients diagnosed with dilated NCCM were alive with normal cardiac function at 15-year follow-up [7]. A group in Toronto found a transplant-free survival rate after 3 years of $72 \%$ in a group of pediatric NCCM patients, of which $77.3 \%$ had cardiac dilatation [29]. In addition, a Japanese study reported poor outcomes (death/HTx) in only $11.1 \%$ of the pediatric patients after a median follow-up of 6 years (cardiac dilation in 33.3\% of the patients) [79]. Colleagues in New York found a median transplant-free survival of 1.17 years after the presentation in pediatric NCCM patients (DCM phenotype in 46\%) [34].

Differences in outcome can inter alia be explained by the composition of the cohort. Pediatric patients diagnosed with
NCCM with mixed cardiomyopathy phenotypes have an increased risk for death or transplant compared (hazard ratio of 6.35) to NCCM patients without a mixed cardiomyopathy phenotype [19]. Furthermore, left ventricle dilatation is found to be an independent predictor of poor outcome (HTx/death) [34]. Likewise, a lower 5-year transplant-free survival was found in NCCM pediatric patients with a concomitant CMP in comparison to pediatric NCCM patients without concomitant CMP [28]. Time to death or HTx in children with dilated NCCM, however, did not differ from children with isolated $\operatorname{DCM}(p=0.22)$. Composite end points at 5 years were $37 \%$ in the dilated NCCM group and 47\% with only DCM [19].

Interestingly, patients with NCCM and Barth syndrome showed a trend towards better survival at 15 years than patients with NCCM alone ( $n=7,71 \%$ vs $36 \%, p=0.08$ ) [7]. The routine screening in families with Bart syndrome, and the consequential early diagnosis, may have contributed to this.

Furthermore, in the overall pediatric NCCM population, presentation in the first year of life is associated with increased mortality (HR 2.1, $p=0.02$ ) [19, 28], and most deaths (90\%) occur in the first year after the diagnosis of NCCM. This emphasizes the need for internationally accepted diagnostic criteria, which can be utilized to detect NCCM in an early stage of the disease.

\section{Management}

No specific medical or surgical treatment strategy has yet been successfully introduced for the treatment of NCCM. Nevertheless, medical treatment with a beta-blocker, an angiotensin-converting enzyme inhibitor, and/or an angiotensin II receptor blocker might lead to favorable remodeling of the left ventricle [80]. No data exist for children with NCCM using newer therapies such as sacubitril/ valsartan combination. Furthermore, children diagnosed with NCCM should be monitored closely for complications and deteriorations, and any arrhythmia should be treated according to clinical protocols. The effectiveness of ICD therapy needs to be evaluated in these patients. Additional effort should be made to determine if preventive anticoagulation or antiplatelet therapy is warranted in these children.

If, however, cardiac function deteriorates despite maximal medical treatment in children with end-stage heart failure due to NCCM, the only viable option for treatment is HTx. Overall, $4 \%$ of the children listed for HTx in North America were diagnosed with isolated NCCM. There was no difference in waiting list mortality or survival after HTx between pediatric NCCM patients and pediatric DCM patients. However, there was a decreased freedom of infection in NCCM patients compared to DCM patients under 1 year of age. Known NCCM-immune deficiencies may have contributed to this fact. However, 
refusing HTx to pediatric NCCM patients is not grounded based on the diagnosis alone, since graft rejection and mortality after HTx is similar in NCCM and DCM patients [70]. Experience with mechanical circulatory support in pediatric patients with NCCM is scarce and limited to single cases [81-83]. Though it is feasible, this therapy is reserved for only NCCM patients with single, predominantly left, ventricular failure. Larger studies are warranted to depict the outcomes of pediatric NCCM patients treated with mechanical circulatory support.

\section{Complications}

NCCM is often associated with various tachyarrhythmias, with incidence rates reported between 0 and $43 \%$ (Table 1) [21, 28-32, 36-39]. The presence of arrhythmia is a known risk factor for several morbidities and mortality in children with NCCM [28]. Therefore, more research on the exact incidence and severity of the various forms of arrhythmias and management of complications of pediatric NCCM patients is warranted.

Another association frequently made with NCCM is the occurrence of stroke and other thromboembolic events. It is believed that blood clots are likely to form in the honeycomb-like structure of the myocardium, causing regions of blood stasis in NCCM patients. Reported incidence of thromboembolism in NCCM children ranges from 0 to $29 \%$ (Table 1) [10, 21, 29-33, 35-37, 39]. The occurrence of stroke was only found in one cohort study (2 patients affected, 29\%) [21]. In children with NCCM on the HTx waiting list, stroke occurred in 4\% [70]. Interestingly, most studies (7/11) on embolisms in NCCM children report an incidence of 0\% (Table 1) [29-32, 35-37].

In adults, however, the incidence of embolism ranges from 5 to $38 \%$ and is therefore one of the most feared complications in NCCM patients. Consequently, antithrombotic prophylaxis is prescribed by some medical centers [84].

More research on the exact incidence of thromboembolic events in NCCM children is warranted to evaluate if anticoagulation or antiplatelet therapy in these children is necessary and justified.

\section{Future perspective}

Considering the rareness of the disease, there is a need for an international consensus on the diagnostic criteria and classification of NCCM as a distinct form of cardiomyopathy. Echocardiography and other minimal invasive diagnostics should be further studied to enable physicians to diagnose NCCM through simple, non-invasive and widely available tools. A joint international effort with attention to the different subtypes of NCCM would be beneficial for the cardiac society.
Hopefully, the near future will witness, (inter)national, multicenter collaborations to collect cases in a registry in order to have data from which the outcome and impact of management strategies in these patients can be evaluated, to improve clinical management of patients and their families.

\section{Conclusion}

Childhood NCCM is a novel, yet rare clinical entity with heterogeneous phenotypes, clinical presentation, and potentially fatal complications. Clinical presentation varies widely from asymptomatic to congestive heart failure and sudden cardiac arrest. The diagnosis of NCCM, performed through echocardiography or CMR, would less frequently be missed through raised awareness and operator training. Systematic DNA testing is encouraged since in nearly half cases a genetic cause can be identified, and genetics may predict clinical outcome. There is a need for an international consensus on the classification of NCCM as distinct cardiomyopathy and its diagnostic criteria. Finally, efforts are needed to collect cases in a registry in order to recognize outcome patterns and evaluate the impact of management strategies in these patients.

\section{Clinical perspectives}

- Noncompaction cardiomyopathy (NCCM) is a novel, yet rare clinical entity, but nevertheless the third most common cardiomyopathy in childhood and is associated with congestive heart failure, arrhythmias and/or thromboembolic events.

- This state-of-the-art review provides an overview of pediatric NCCM including the epidemiology, natural history, genetics, clinical presentation, prognosis, and therapeutic options of NCCM in pediatric patients.

- There is an urgent need for an international consensus on the classification of NCCM, the diagnostic criteria, and use of genetic testing in the daily clinical practice.

- Finally, an effort should be made to collect cases in a multicenter, international registry in order to evaluate the outcome and impact of management strategies in these patients.

Open Access This article is licensed under a Creative Commons Attribution 4.0 International License, which permits use, sharing, adaptation, distribution and reproduction in any medium or format, as long as you give appropriate credit to the original author(s) and the source, provide a link to the Creative Commons licence, and indicate if changes were made. The images or other third party material in this article are included in the article's Creative Commons licence, unless indicated otherwise in a credit line to the material. If material is not included in the article's Creative Commons licence and your intended use is not permitted by statutory regulation or exceeds the permitted use, you will need to obtain permission directly from the copyright holder. To view a copy of this licence, visit http://creativecommons.org/licenses/by/4.0/. 


\section{References}

1. Maron BJ, Towbin JA, Thiene G, Antzelevitch C, Corrado D, Arnett D et al (2006) Contemporary definitions and classification of the cardiomyopathies: an American Heart Association Scientific Statement from the Council on Clinical Cardiology, Heart Failure and Transplantation Committee; Quality of Care and Outcomes Research and Functional Genomics and Translational Biology Interdisciplinary Working Groups; and Council on Epidemiology and Prevention. Circulation 113(14):1807-16

2. Engberding R, Bender F (1984) Identification of a rare congenital anomaly of the myocardium by two-dimensional echocardiography: persistence of isolated myocardial sinusoids. Am J Cardiol 53(11):1733-4

3. Finsterer J, Stollberger C (1998) Hypertrabeculated left ventricle in mitochondriopathy. Heart (British Cardiac Society) 80(6):632

4. Jenni R, Oechslin E, Schneider J, Attenhofer Jost C, Kaufmann PA (2001) Echocardiographic and pathoanatomical characteristics of isolated left ventricular non-compaction: a step towards classification as a distinct cardiomyopathy. Heart 86(6):666-71

5. Engberding R, Gerecke B (2019) Noncompaction Cardiomyopathy, a novel clinical entity (historical perspective). In: Caliskan K, Soliman OI, ten Cate FJ (eds) Noncompaction Cardiomyopathy. Springer International Publishing, Cham, pp 1-16

6. Lee TM, Hsu DT, Kantor P, Towbin JA, Ware SM, Colan SD et al (2017) Pediatric cardiomyopathies. Circ Res 121(7):855-73

7. Shi WY, Moreno-Betancur M, Nugent AW, Cheung M, Colan S, Turner C et al (2018) Long-term outcomes of childhood left ventricular noncompaction cardiomyopathy: results from a national population-based study. Circulation 138(4):367-76

8. Udeoji DU, Philip KJ, Morrissey RP, Phan A, Schwarz ER (2013) Left ventricular noncompaction cardiomyopathy: updated review. Ther Adv Cardiovasc Dis 7(5):260-73

9. Miller EM, Hinton RB, Czosek R, Lorts A, Parrott A, Shikany AR et al (2017) Genetic testing in pediatric left ventricular noncompaction. Circ Cardiovasc Genet 10(6)

10. Wang C, Takasaki A, Watanabe Ozawa S, Nakaoka H, Okabe M, Miyao N et al (2017) Long-term prognosis of patients with left ventricular noncompaction- comparison between infantile and juvenile types. Circ J 81(5):694-700

11. Freedom RM, Yoo SJ, Perrin D, Taylor G, Petersen S, Anderson RH (2005) The morphological spectrum of ventricular noncompaction. Cardiol Young 15(4):345-64

12. Jenni R, Goebel N, Tartini R, Schneider J, Arbenz U, Oelz O (1986) Persisting myocardial sinusoids of both ventricles as an isolated anomaly: echocardiographic, angiographic, and pathologic anatomical findings. Cardiovasc Intervent Radiol 9(3):127-31

13. van Waning JI, Caliskan K, Hoedemaekers YM, van SpaendonckZwarts KY, Baas AF, Boekholdt SM et al (2018) Genetics, clinical features, and long-term outcome of noncompaction cardiomyopathy. J Am Coll Cardiol 71(7):711-22

14. Hoedemaekers YM, Cohen-Overbeek TE, Frohn-Mulder IM, Dooijes D, Majoor-Krakauer DF (2013) Prenatal ultrasound diagnosis of MYH7 non-compaction cardiomyopathy. Ultrasound Obstet Gynecol: the Official J Int Soc Ultrasound Obstet and Gynecol 41(3):336-9

15. Stollberger C, Wegner C, Benatar A, Chin TK, Dangel J, MajoorKrakauer D et al (2016) Postnatal outcome of fetal left ventricular hypertrabeculation/noncompaction. Pediatr Cardiol 37(5):919-24

16. Bellet S, Gouley BA (1932) Congenital heart disease with multiple cardiac anomalies. Am J Med Sci 183(4):458-64

17. Elliott $\mathrm{P}$, Andersson B, Arbustini E, Bilinska Z, Cecchi F, Charron $P$ et al (2008) Classification of the cardiomyopathies: a position statement from the European Society Of Cardiology Working
Group on Myocardial and Pericardial Diseases. Eur Heart J 29(2):270-6

18. Soliman OI, McGhie J, ten Cate FJ, Paelinck BP, Caliskan K (2019) Multimodality imaging, diagnostic challenges and proposed diagnostic algorithm for noncompaction cardiomyopathy. In: Caliskan K, Soliman OI, ten Cate FJ (eds) Noncompaction Cardiomyopathy. Springer International Publishing, Cham, pp $17-40$

19. Jefferies JL, Wilkinson JD, Sleeper LA, Colan SD, Lu M, Pahl E et al (2015) Cardiomyopathy phenotypes and outcomes for children with left ventricular myocardial noncompaction: results from the pediatric cardiomyopathy registry. J Card Fail 21(11):877-84

20. Liu Y, Chen H, Shou W (2018) Potential Common pathogenic pathways for the left ventricular noncompaction cardiomyopathy (LVNC). Pediatr Cardiol

21. Chin TK, Perloff JK, Williams RG, Jue K, Mohrmann R (1990) Isolated noncompaction of left ventricular myocardium. A study of eight cases. Circulation 82(2):507-13

22. Handlos P, Gruszka T, Stankova M, Marecova K, Joukal M (2017) Biventricular noncompaction cardiomyopathy with malignant arrhythmia as a cause of sudden death. Forensic Sci Med Pathol 13(4):495-9

23. Cohen PJ, Prahlow JA (2015) Sudden death due to biventricular non-compaction cardiomyopathy in a 14-year-old. Forensic Sci Med Pathol 11(1):92-8

24. Sirin BH, Kurdal AT, Iskesen I, Cerrahoglu M (2010) Right ventricular outflow obstruction of the patient with biventricular noncompaction. Thorac Cardiovasc Surg 58(6):364-6

25. Tomar M, Radhakrishnan S (2009) Biventricular noncompaction: a rare cause of fetal distress and tricuspid regurgitation. Images Paediatr Cardiol 11(4):1-5

26. Grattan MJ, Buffo-Sequeira I, Fortier M, Pepelassis D (2009) Biventricular noncompaction in a patient with dextrocardia/dextroversion diagnosed with cardiac magnetic resonance imaging. Can J Cardiol 25(9):e335-6

27. Tigen K, Karaahmet T, Gurel E, Cevik C, Basaran Y (2008) Biventricular noncompaction: a case report. Echocardiography 25(9):993-6

28. Brescia ST, Rossano JW, Pignatelli R, Jefferies JL, Price JF, Decker JA et al (2013) Mortality and sudden death in pediatric left ventricular noncompaction in a tertiary referral center. Circulation 127(22):2202-8

29. Wald R, Veldtman G, Golding F, Kirsh J, McCrindle B, Benson L (2004) Determinants of outcome in isolated ventricular noncompaction in childhood. Am J Cardiol 94(12):1581-4

30. Ozkutlu S, Ayabakan C, Celiker A, Elshershari H (2002) Noncompaction of ventricular myocardium: a study of twelve patients. J Am Soc Echocardiogr 15(12):1523-8

31. El-Menyar AA, Gendi SM, Numan MT (2007) Noncompaction cardiomyopathy in the State of Qatar. Saudi Med J 28(3):429-34

32. Ozgur S, Senocak F, Orun UA, Ocal B, Karademir S, Dogan $V$ et al (2011) Ventricular non-compaction in children: clinical characteristics and course. Interact Cardiovasc Thorac Surg 12(3):370-3

33. Tian T, Yang Y, Zhou L, Luo F, Li Y, Fan P et al (2018) Left ventricular non-compaction: a cardiomyopathy with acceptable prognosis in children. Heart Lung Circ 27(1):28-32

34. Zuckerman WA, Richmond ME, Singh RK, Carroll SJ, Starc TJ, Addonizio LJ (2011) Left-ventricular noncompaction in a pediatric population: predictors of survival. Pediatr Cardiol 32(4):406-12

35. Ergul Y, Nisli K, Demirel A, Varkal MA, Oner N, Dursun M et al (2011) Left ventricular non-compaction in children and adolescents: clinical features, treatment and follow-up. Cardiol J 18(2):176-84 
36. Koh C, Lee PW, Yung TC, Lun KS, Cheung YF (2009) Left ventricular noncompaction in children. Congenit Heart Dis 4(4):288-94

37. Tsai SF, Ebenroth ES, Hurwitz RA, Cordes TM, Schamberger MS, Batra AS (2009) Is left ventricular noncompaction in children truly an isolated lesion? Pediatr Cardiol 30(5):597-602

38. Fazio G, Pipitone S, Iacona MA, Marchi S, Mongiovi M, Zito R et al (2007) The noncompaction of the left ventricular myocardium: our paediatric experience. J Cardiovasc Med (Hagerstown) 8(11):904-8

39. Lilje C, Razek V, Joyce JJ, Rau T, Finckh BF, Weiss F et al (2006) Complications of non-compaction of the left ventricular myocardium in a paediatric population: a prospective study. Eur Heart $\mathbf{J}$ 27(15):1855-60

40. Stollberger C, Wegner C, Finsterer J (2019) Left ventricular hypertrabeculation/noncompaction, cardiac phenotype, and neuromuscular disorders. Herz 44(7):659-65

41. Finsterer J, Stollberger C, Fazio G (2010) Neuromuscular disorders in left ventricular hypertrabeculation/noncompaction. Curr Pharm Des 16(26):2895-904

42. Stollberger C, Finsterer J, Blazek G, Bittner RE (1996) Left ventricular non-compaction in a patient with Becker's muscular dystrophy. Heart (British Cardiac Society) 76(4):380

43. Statile CJ, Taylor MD, Mazur W, Cripe LH, King E, Pratt J et al (2013) Left ventricular noncompaction in Duchenne muscular dystrophy. J Cardiovasc Magn Reson 15:67

44. Kimura K, Takenaka K, Ebihara A, Uno K, Morita H, Nakajima T et al (2013) Prognostic impact of left ventricular noncompaction in patients with Duchenne/Becker muscular dystrophy-prospective multicenter cohort study. Int J Cardiol 168(3):1900-4

45. Arunamata A, Punn R, Cuneo B, Bharati S, Silverman NH (2012) Echocardiographic diagnosis and prognosis of fetal left ventricular noncompaction. J Am Soc Echocardiogr: Official Publication of the Am Soc Echocardiogr 25(1):112-20

46. Ozkutlu S, Bostan O, Karagoz T, Deren O, Tekinalp G (2007) Prenatal diagnosis of isolated non-compaction of the ventricular myocardium: study of six cases. Pediatr Int: Official J Japan Pediatr Soc 49(2):172-6

47. Tian L, Zhou Q, Zhou J, Zeng S, Cao D, Zhang M (2015) Ventricular non-compaction cardiomyopathy: prenatal diagnosis and pathology. Prenatal Diagn 35(3):221-7

48. Weber R, Kantor P, Chitayat D, Friedberg MK, Golding F, Mertens L et al (2014) Spectrum and outcome of primary cardiomyopathies diagnosed during fetal life. JACC Heart Fail 2(4):403-11

49. Stollberger C, Wegner C, Finsterer J (2015) Fetal Ventricular Hypertrabeculation/noncompaction: clinical presentation, genetics, associated cardiac and extracardiac abnormalities and outcome. Pediatr Cardiol 36(7):1319-26

50. Gardiner HM (2018) Advances in fetal echocardiography. Semin Fetal Neonatal Med 23(2):112-8

51. Arbustini E, Favalli V, Narula N, Serio A, Grasso M (2016) Left ventricular noncompaction: a distinct genetic cardiomyopathy? J Am Coll Cardiol 68(9):949-66

52. Finsterer J (2009) Cardiogenetics, neurogenetics, and pathogenetics of left ventricular hypertrabeculation/noncompaction. Pediatr Cardiol 30(5):659-81

53. Finsterer J, Stollberger C, Towbin JA (2017) Left ventricular noncompaction cardiomyopathy: cardiac, neuromuscular, and genetic factors. Nat Rev Cardiol 14(4):224-37

54. Dong X, Fan P, Tian T, Yang Y, Xiao Y, Yang K et al (2017) Recent advancements in the molecular genetics of left ventricular noncompaction cardiomyopathy. Clin Chim Acta; Int J Clin Chem 465:40-4

55. van Waning JI, Caliskan K, Michels M, Schinkel AFL, Hirsch A, Dalinghaus $\mathrm{M}$ et al (2019) Cardiac phenotypes, genetics, and risks in familial noncompaction cardiomyopathy. J Am Coll Cardiol 73(13):1601-11

56. Klaassen S, Probst S, Oechslin E, Gerull B, Krings G, Schuler P et al (2008) Mutations in sarcomere protein genes in left ventricular noncompaction. Circulation 117(22):2893-901

57. Dellefave LM, Pytel P, Mewborn S, Mora B, Guris DL, Fedson $S$ et al (2009) Sarcomere mutations in cardiomyopathy with left ventricular hypertrabeculation. Circ Cardiovasc Genet 2(5):442-9

58. Towbin JA, Bowles NE (2002) The failing heart. Nature 415(6868):227-33

59. Towbin JA, Jefferies JL (2017) Cardiomyopathies due to left ventricular noncompaction, mitochondrial and storage diseases, and inborn errors of metabolism. Circ Res 121(7):838-54

60. van Waning JI, Moesker J, Heijsman D, Boersma E, MajoorKrakauer D (2019) Systematic review of genotype-phenotype correlations in noncompaction cardiomyopathy. J Am Heart Assoc 8(23): 012993

61. Bione S, D'Adamo P, Maestrini E, Gedeon AK, Bolhuis PA, Toniolo D (1996) A novel X-linked gene, G4.5. is responsible for Barth syndrome. Nat Genet 12(4):385-9

62. Bleyl SB, Mumford BR, Thompson V, Carey JC, Pysher TJ, Chin TK et al (1997) Neonatal, lethal noncompaction of the left ventricular myocardium is allelic with Barth syndrome. Am J Hum Genet 61(4):868-72

63. Clarke SL, Bowron A, Gonzalez IL, Groves SJ, Newbury-Ecob R, Clayton N et al (2013) Barth syndrome. Orphanet J Rare Dis 8:23

64. Neustein HB, Lurie PR, Dahms B, Takahashi M (1979) An $\mathrm{X}$-linked recessive cardiomyopathy with abnormal mitochondria. Pediatrics 64(1):24-9

65. Barth PG, Scholte HR, Berden JA, Van der Klei-Van Moorsel JM, Luyt-Houwen IE, Van 't Veer-Korthof ET et al (1983) An $\mathrm{X}$-linked mitochondrial disease affecting cardiac muscle, skeletal muscle and neutrophil leucocytes. J Neurol Sci 62(1-3):327-55

66. Roberts AE, Nixon C, Steward CG, Gauvreau K, Maisenbacher M, Fletcher M et al (2012) The Barth Syndrome Registry: distinguishing disease characteristics and growth data from a longitudinal study. Am J Med Genet A 158A(11):2726-32

67. Sasse-Klaassen S, Gerull B, Oechslin E, Jenni R, Thierfelder L (2003) Isolated noncompaction of the left ventricular myocardium in the adult is an autosomal dominant disorder in the majority of patients. Am J Med Genet A 119A(2):162-7

68. Tang S, Batra A, Zhang Y, Ebenroth ES, Huang T (2010) Left ventricular noncompaction is associated with mutations in the mitochondrial genome. Mitochondrion 10(4):350-7

69. Pignatelli RH, McMahon CJ, Dreyer WJ, Denfield SW, Price J, Belmont JW et al (2003) Clinical characterization of left ventricular noncompaction in children: a relatively common form of cardiomyopathy. Circulation 108(21):2672-8

70. Lal AK, Pruitt E, Hong BJ, Lin KY, Feingold B (2016) Left ventricular non-compaction cardiomyopathy in children listed for heart transplant: analysis from the Pediatric Heart Transplant Study Group. J Heart Lung Transplant 35(4):540-2

71. Stollberger C, Finsterer J, Blazek G (2002) Left ventricular hypertrabeculation/noncompaction and association with additional cardiac abnormalities and neuromuscular disorders. Am J Cardiol 90(8):899-902

72. Oechslin EN, Attenhofer Jost CH, Rojas JR, Kaufmann PA, Jenni $\mathrm{R}$ (2000) Long-term follow-up of 34 adults with isolated left ventricular noncompaction: a distinct cardiomyopathy with poor prognosis. J Am Coll Cardiol 36(2):493-500

73. Kohli SK, Pantazis AA, Shah JS, Adeyemi B, Jackson G, McKenna WJ et al (2008) Diagnosis of left-ventricular non-compaction in patients with left-ventricular systolic dysfunction: time for a reappraisal of diagnostic criteria? Eur Heart J 29(1):89-95 
74. Petersen SE, Selvanayagam JB, Wiesmann F, Robson MD, Francis JM, Anderson RH et al (2005) Left ventricular non-compaction: insights from cardiovascular magnetic resonance imaging. J Am Coll Cardiol 46(1):101-5

75. Jacquier A, Thuny F, Jop B, Giorgi R, Cohen F, Gaubert JY et al (2010) Measurement of trabeculated left ventricular mass using cardiac magnetic resonance imaging in the diagnosis of left ventricular non-compaction. Eur Heart J 31(9):1098-104

76. Weir-McCall JR, Yeap PM, Papagiorcopulo C, Fitzgerald K, Gandy SJ, Lambert M et al (2016) Left ventricular noncompaction: anatomical phenotype or distinct cardiomyopathy? J Am Coll Cardiol 68(20):2157-65

77. van Waning JI, Caliskan K, Chelu RG, van der Velde N, Pezzato A, Michels M et al (2020) Diagnostic cardiovascular magnetic resonance imaging criteria in noncompaction cardiomyopathy and the yield of genetic testing. Can J Cardiol

78. Yubbu P, Nawaytou HM, Calderon-Anyosa R, Banerjee A (2018) Diagnostic value of myocardial deformation pattern in children with noncompaction cardiomyopathy. Int J Cardiovasc Imaging

79. Ichida F, Hamamichi Y, Miyawaki T, Ono Y, Kamiya T, Akagi $\mathrm{T}$ et al (1999) Clinical features of isolated noncompaction of the ventricular myocardium: long-term clinical course, hemodynamic properties, and genetic background. J Am Coll Cardiol 34(1):233-40
80. Parent JJ, Towbin JA, Jefferies JL (2016) Medical therapy leads to favorable remodeling in left ventricular non-compaction cardiomyopathy: dilated phenotype. Pediatr Cardiol 37(4):674-7

81. Uribarri A, Rojas SV, Avsar M, Hanke JS, Napp LC, Berliner D et al (2015) First series of mechanical circulatory support in non-compaction cardiomyopathy: Is LVAD implantation a safe alternative? Int J Cardiol 197:128-32

82. Balsara KR, Bierhals A, Vader J, Pasque MK, Itoh A (2017) Implantation of left ventricular assist device in a patient with left ventricular non-compaction. J Card Surg 32(2):159-61

83. Huenges K, Panholzer B, Cremer J, Haneya A (2018) Ventricular assist device implantation in a young patient with non-compaction cardiomyopathy and hereditary spherocytosis. Eur J Cardiothorac Surg: Official J Eur Assoc Cardiothorac Surg 53(4):879-80

84. Chen K, Williams S, Chan AK, Mondal TK (2013) Thrombosis and embolism in pediatric cardiomyopathy. Blood Coagul Fibrinolysis 24(3):221-30

Publisher's Note Springer Nature remains neutral with regard to jurisdictional claims in published maps and institutional affiliations. 